\title{
Meaning vs. Power: Are Thick Description and Power Analysis Intrinsically at Odds? Response to Interpretation, Explanation, and Clifford Geertz
}

\author{
Jason Springs*
}

University of Notre Dame - Kroc Institute for International Peace Studies

\begin{abstract}
This paper responds critically and synthetically to forgoing papers by Kevin Jung, Robert Segal, and Stephen Bush. Placing their respective arguments into conversation helpfully illuminates the methodological multidimensionality and improvisational character of Geertz's account of interpretation and explanation. I argue that these features of Geertz's work enable it to simultaneously attend to meaning, power, identity, and experience in understanding and assessing religious practices and cultural formations.
\end{abstract}

The above papers complementarily raise questions, criticisms, and open potentially fruitful paths for developing Geertz's work in the study of religion. Lee gives us a paper with a two-fold objective. The first explicates thick description's compatibility with Donald Davidson's conception of "radical interpretation." The second is a constructive gesture toward a "normative theory of religion" constructed in terms of Geertz's account of ethos and worldview. I focus on Lee's first objective, briefly positioning it amid several important conversations in the study of religion. I then invite Lee to think a bit more specifically about the difference it makes to read Geertz with Davidsonian eyes. Segal's contribution challenges the tendency to pigeonhole Geertz as concerned solely with the interpretation of meanings in contrast to explanation. He demonstrates how Geerz subverts such a dichotomy by innovatively integrating both interpretation and explanation. Bush takes issue both with those who think that Geertz might accommodate attention to power analysis, and challenges Talal Asad's widely influential criticisms of Geertz (Asad 1993). ${ }^{1}$

The papers by Segal and Bush speak to one another provocatively. After inviting Lee to expand upon his central claims, I place the latter two papers into conversation, letting the tensions between them emerge. I then demonstrate how an accurate grasp of Geertz's approach to the study of culture (and religion as a cultural "system," in particular) requires recognizing his approach as not simply non-reductionist, but positively eclectic-even improvisational-in the methodological categories that he deploys. Because of this, I argue, Geertz's analytical approach is quite capable of discerning and critically interrogating dimensions of both meaning and power in ritual and symbolic practices, and in cultural systems more broadly.

\section{What's the Use in Calling Geertz a Davidsonian?}

Lee provides a corrective repositioning of Geertz in a provocative conversation in the areas of theory and method of the study of religion (Frankenberry 2002). Many scholars of religion have been persuaded that Donald Davidson's work helps defuse the conceptual scheme relativism according to which normative judgments or truth claims about the 
world will be relative to the conceptual scheme within which those claims are made (Bowlin \& Stromberg 1997; Davidson 2001). Some read Geertz as an exponent of the very "conceptual scheme" analysis (and thus liable to the kind of relativism) that Davidson overturns (Godlove 1997, 74-84). Lee not only resists this positioning of Geertz, he claims that a particularly productive way of describing Geertz's project is to read it as a variety of Davidsonian "radical interpretation." If he succeeds, Lee will have corrected the tendency to lump Geertz under the category of "scheme-content dualism," correspondence theory, and cognitivism about belief.

According to Lee, charges that Geertz is a representationalist and adheres to a correspondence theory of truth not only obscure the contours of his work, but that such charges are tenable only insofar as one reads Geertz in an entirely uncharitable way (5). Lee makes this point quite persuasively, in my judgment. And yet, it is important to keep in mind that, reading Geertz charitably, and redescribing him in Davidsonian terms, are two different things. The question arises: what does reading Geertz as a Davidsonian get you that a more charitable (perhaps simply more accurate) reading of Geertz does not? What new light does it shed on Geertz's work? What does it further enable a Geertzinspired ethnographer, cultural analyst, or scholar of religion to do? Does it expand or enrich the purposes and analytical power of thick description in any way? This is, I think, what Geertz would want to know. Does Lee's account push Geertz's work in potentially constructive directions among cultural theorists and philosophers of religion?

Bush sets out to understand how it is, precisely, that meaning and power are, as Geertz claimed late in his career, "hopelessly entangled" and "mutually implicative" (Geertz 2000, 184). Bush then compares Geertz and Talal Asad's positions on the complex interrelation of meaning and power in the study of cultural formations. He finds things to puzzle over on both sides. It turns out, as Bush exposes in a particularly deft move, Asad's refusal of symbolic meaning in favor of power-power understood as the operation of "disciplinary and coercive practices" in "shaping subjects," forming selves, and "constituting hierarchies"- -implicates Asad in a bit of self-deception. As Bush concludes, "the view that sees religion as power is committed to a view of religion as meaning" (3).

Bush's claim about the enmeshment of meaning and power appears consistent with Geertz's claim that meaning and power are "hopelessly entangled" and "mutually implicative." Bush argues that this is not what Geertz means. In fact, he argues that Geertz's approach to symbolic meaning is "not suitable for the analysis of power." As Bush has it, power analysts focus upon the socialization of persons into "particular habits that dispose them to feel, desire, perceive, and comport themselves in determinate ways." It is crucial to note, on Bush's account, this shaping of habits and dispositions is something of which the subject cannot be consciously aware (4). For Geertz, by contrast, as Bush reads him, symbol-users will be aware of the meanings of the symbols that they use. This categorically distinguishes Geertz's concern with meanings from concerns about power. "The meaning of the symbol, 'is the meaning particular social actions have for the actors whose actions they are', Geertz says" (Geertz 1973, 27, Bush's italics). This reading emphasizes that the Geertzian anthropologist is charged with the task of "reading the culture 'over the shoulders' of whose cultures it is." According to Bush's gloss of these lines from Geertz, "If you asked them what a ritual, gesture, or term meant, they would be able to tell you" (4). Here the papers by Segal and Bush begin to speak to one another in a particularly instructive way.

Segal says clearly from the start that interpretation may be interpretation of how things are from the actor's point of view. This does not mean that the meaning identified and described will be one that the actor will consciously recognize or endorse. As Segal puts 
it, "Even if an interpretation is necessarily from the actor's point of view, it need not be limited to the actor's conscious point of view. The meaning found by interpreters are commonly ones of which the actor is unaware" (2). At the same time, Segal cautions, explanation need not necessarily depart from what the religious adherent or actor would recognize or accept. Segal emphasizes the fact that the Geertzian anthropologist does not peer over the shoulder of her subjects and record what they understand themselves to be up to purely and simply. Such analysis contains this as a central element, to be sure. Geertz does say, for instance, that thickly descriptive interpretations aim to be "actor oriented." But he is careful to properly understand what it means, and does not mean, to say this. Segal suggests that an account that limits meanings to those of which the actor consciously aware (especially understood in terms of what the actor would be able to tell the analyst, or even willingly endorse) is too thin an account of meaning and interpretation for Geertz.

Segal's reading points us to the fact that, for the Geertzian ethnographer, the cultural contexts and social actions being described are ensembles of texts, which are themselves ensembles. In "straining to read over the shoulder" of his or her subjects, the ethnographer aims to construct a reading of a manuscript that is "foreign, faded, full of ellipses, incoherencies, suspicious emendations, and tendentious commentaries..." (Geertz 1973, p. 10). The meaning-even actor oriented meaning-may well overrun what any particular actor takes the meaning of a social action or symbol to be. Geertz expresses the complex interrelation of interpretation and explanation in his discussion of the ethnographer's uses of "experience near" and "experience distant” concepts (Geertz 1983, p. 57).

"Experience near" refers to the concepts that a subject of study or "native informant" might "naturally and effortlessly" use to tell one what he understands himself and his compatriots to be up to-what they "see, feel, think, imagine, and so on, and which he would readily understand when similarly applied by others" (Geertz 1983). "Experience distant" concepts are those categories that the cultural analyst or specialist brings to bear in the process of constructing a reading of, and extrapolating from, what one's native informants understand themselves to be doing. ${ }^{2}$ Geertz is emphatic that "you don't have to be one to know one." In other words, the ethnographer should avoid attempting to think like, "achieve communion with," or step into the shoes of her subjects. Nor should the analyst privilege by default reports from their point of view. The analyst's challenge, rather, is to artfully and generatively integrate experience-near and experience-distant concepts:

[To] produce an interpretation of the way a people lives which is neither imprisoned in their mental horizons, an ethnography of witchcraft as written by a witch, nor systematically deaf to the distinctive tonalities of their existence, an ethnography of witchcraft as written by a geometer (Geertz 1983, p. 57).

This task requires a charitable grasp of the uses of concepts native to the context under analysis, as well as placing those concepts in "illuminating connections with experience distant" concepts (Geertz 1983, 58). "The trick is to figure out what the devil they think they are up to," Geertz says, in a line that appears to vindicate Bush's claim about the subject's conscious awareness of meaning as the object of Geertzian analysis. "In one sense of course no one knows this better than they do themselves." But Geertz then crucially pivots away from this claim, adding, "But in another sense, that simple truism is simply not true." He continues:

People use experience-near concepts spontaneously, un-self-consciously, as it were colloquially; they do not, except fleetingly and on occasion, recognize that there are any 'concepts' involved at all. That is what experience-near means-that ideas and the realities they inform are naturally and indissolubly bound up together" (58). 
This un-self-consciousness-perhaps implicit or practical grasp of experience-near concepts-is consistent with Gilbert Ryle's distinction between "knowing how" and "knowing that," which was so influential for Geertz (Geertz 1973; Chaps. 1, 2; Ryle 1949; Chap. 2). In as far as a symbol is "a vehicle for a conception" in a ritual act or symbolic practice, average, ordinary, everyday practitioners might use the symbol correctly, adeptly-even with a degree of practical excellence-but perhaps not be able to state what the conception "contained" in the symbol is. If pressed, he or she might offer a gloss of the symbol's meaning that is erroneous. Ryle's example is of a boy who learns to play chess, and plays correctly and deftly on the basis of observation and repeated participation in this propriety-laden activity, yet without ever having read or heard-or being able to explicitly articulate-the formal rules of the game. Perhaps more plausibly, some participant in a ritual or symbolic practice, when pressed to state explicitly what her actions or use of a symbol "mean" to some enquiring ethnographer, might reply, "this is simply what we do." It is in their use that symbols have their life, Geertz says (following Wittgenstein), not in the native's conscious explication of their use. To confine the interpretation of meaning of the symbols to what the native reflectively thinks and can articulate runs into what Geertz calls "psychologism"- - "the other great saboteur of cultural analysis." Geertz uses the term "thinking" to refer to "intelligent activity of any sort, and 'meaning' to refer not just to abstract 'concepts' but significance of any sort' (Geertz 1973; p. 405, n. 44, echoing Ryle 2009).

The distinction and dialectical relation between "experience near" and "experience distant" concepts suggests how a Geertz-inspired analyst might make sense of and say something analytically illuminating about (to take Bush's example) a group of boys out on a playground overheard to repeatedly shout at one another the phrase, "Dude, you throw like a girl!" If the analyst directly asked them what this phrase "means," they might very well report that girls throw in a particular way, and that their friend, though a boy, throws like that- "like a girl." In principle, nothing prohibits the Geertzian analyst in question from employing "experience distant" concepts (such as those Bush identifies in Iris Marion Young's work, for instance) with which the ethnographer would construct a reading of the situation that illuminates broader cultural presuppositions and implications of the phrases' meaning in that context. Such a reading might propose, for instance, "The boys and girls in this context are acculturated and habituated so as to physically comport themselves in different ways (i.e. timidly vs. assertively). Moreover, they are socialized so as not to recognize this as a contingent process of socialization (say, the internalization of certain culturally articulated dispositions and habits) that could be otherwise, but rather, as something essential and self-evident to 'being a girl' in contrast to 'being a boy'." Moreover, the analyst might read such uses of the phrase as not only reflecting the shaping and forming of selves, but as further perpetuating perceptions, experiences, acceptable forms of bodily comportment and behavioral patterns. Such a reading is fully consistent with Geertz's description of the disposition-forming impact that cultural systems exert upon the formation of persons. ${ }^{3}$

All this suggests that Segal is on to something important in Geertz when he says that thickly describing what social actions mean at a given place and time is not confined to significances of which the actors are consciously aware. It suggests, moreover, that important elements of the descriptive flexibility and critical potential of what Geertz means by "meaning" get washed out when Bush ascribes to Geertz the claim that "The meaning of the symbol' 'is the meaning particular social actions have for the actors whose actions they are'," and glosses that to mean "If you asked them what a ritual, gesture, or term meant, they would be able to tell you" (4). 
Bush pushes the case that Geertz cannot account for social-structural operations of power-and how they manifest themselves in the shaping and forming of selves, in particular-because Geertz makes the statement that "culture is not a power" in the sense that it does not "cause behavior." This claim comes from a passage in which Geertz says this: "As interworked systems of construable signs, culture is not a power, something to which social events, behaviors, institutions, or processes can be causally attributed; it is a context, something within which they can be intelligently-that is, thickly-described" (Geertz 1973 , p. 14). Bush is right to carefully puzzle over this passage, because if it means what it appears to say (Bush helpfully illustrates with his own example of ethnic conflict in Rwanda), then Geertz's approach conflicts with the nature of practical reasoning (Bush, 6). Moreover, if we read this line as severing belief from behavior, then we find Geertz in a self-contradictory bind. What, for instance, are we to make of the many passages in which Geertz identifies the function and impact of cultural systems - and, in particular, the ways that religious symbols, meanings and practices exert themselves by synthesizing worldview (beliefs) and ethos (a group's way of life)—as uniquely and powerfully motivating behavior, namely, that they "establish powerful, pervasive, long-lasting moods and motivations in men [sic]?"

Here again Bush's and Segal's papers converse instructively, and a clarifying tension begins to emerge. Segal calls attention to Max Weber's influence upon Geertz's account of culture, particularly for understanding the practical impact of dispositions, moods and motivations which religious symbol systems cultivate and evoke (11-12). Acknowledging his debt to Weber, Geertz describes humans as meaning-making animals suspended in webs of significance they themselves have spun. Geertz takes "cultures" to be those webs of meaning into which humans find themselves suspended (Geertz 1968; p. 99; 1973, p. 5). No particular individual spins these "webs," Segal points out. For those caught up in those webs of significance identified as "religious," the "symbol systems" in question evoke certain powerful, long-lasting moods and motivations by synthesizing worldview and ethos. Generally, cultural patterns "institute ...social and psychological processes which shape public behavior" (92). Religious symbol systems shape public behavior in especially profound (Geertz says "coercive") ways. "[R]eligion, by fusing ethos and world view, gives to a set of social values what they perhaps most need to be coercive: an appearance of objectivity. In sacred rituals and myths values are portrayed not as subjective human preferences but as imposed conditions for life implicit in a world with a particular structure" (Geertz 1973, 131).

It would appear that Geertz is caught in a particularly glaring self-contradiction. On one hand, he asserts that "culture does not cause behavior." Three essays further in the same book he argues that religious cultural systems influence-at times coercively_ “a chronic character to the flow of his activity and the quality of his experience" (95). Bush sharpens the risk entailed in this contradiction. If Geertz indeed subscribes to the apparent claim that "culture does not cause behavior," then he has taken up an understanding of culture that "conflicts with the nature of practical reasoning" (6)-a defective and selfdefeating position indeed.

There may be a way to read these lines that resolves their apparent contradictoriness without either ascribing to Geertz a fairly flagrant self-contradiction, or reading him as denying the nature of practical reasoning. Read with careful attention to its context, the phrase "culture does not cause behavior" appears in the transitional paragraphs following Section III of "Thick Description," where Geertz overviews the predominant theoretical tendencies in the study of culture at the time he was writing (i.e. the "theoretical muddlement in contemporary anthropology" (Geertz 1973, p. 11). Here he introduces his own "semiotic concept of culture" as an alternative that renders irrelevant (according to 
Geertz) the regnant debates over whether "culture" is "subjective" vs. "objective," "patterned conduct" vs. "a frame of mind" (or some combination of the two), as well as all of the labeling that accompanied these ("idealist!"-_"materialist!"; "mentalist!""behaviorist!”; “impressionist!"- “positivist!”). The prevailing temptations amidst these debates are to either reify "culture" (to make it, as Geertz said, a " 'super-organic' reality with forces and purposes of its own"), or reduce it to "a brute pattern of behavioral events" (Geertz 1973, pp. 10-11). In short, here Geertz is conducting a theoretical ground-clearing exercise of sorts. His assertions that "culture is not a power" and does not "cause behavior" (among other things he says that culture is not, and does not do, in these passages) counters accounts that reify "culture"- - that construe it as a "reality with force and purposes of its own," and thus as a causal determinant of behavior. On this reading, Geertz's denial that culture "causes behavior" is indexed to a context-specific deterministic conception of culture that he is rejecting and countering (i.e. culture as "a power," and the accompanying fallacy of reification). This refusal is consistent with his further claim that "culture" is more like a context within which behavior can be described. Following Weber, cultural systems are like "webs of meaning" that fill out those contexts, and acculturation into those contexts shapes and forms behavior by inclining or disposing people to behave in certain ways (i.e. cultivating dispositions, sensibilities, proclivities, tendencies and habits in them). ${ }^{5}$

On my proposed reading, the impact of the ethos/worldview synthesis through religious symbol systems does not exert "coercive" force as a distinct causal mechanism dictating behavior or directly causing any specific action. It would not, to apply it to Bush's apt example, dictate that the machete-clenched hand of the Rwandan Hutu reach out and cleave the skull of his Tutsi next door neighbor. However, it would, under the right circumstances, dispose, incline, or make the Hutu likely to behave in that way (i.e. circumstances where, for instance, the cultural significances and historical invidiousness of Hutu and Tutsi identity-associated dispositions or proclivities had been brought to the surface, aggravated, manipulated, mobilized and whipped into frenzy for religious- and/or ethno-nationalist purposes, so as to inspire violence and even genocide). In fact, on the reading I am proposing, the Rwandan genocide is a case for which Geertz's thickly descriptive approach powerfully illuminates the multiple, inter-penetrating layers of nationalist, ethnic, tribal, historical, colonialist sources of the moods, motivations, sensibilities, and social significances that shaped behavior generally in that context, and which, as a historical matter of fact, were mobilized and manipulated in ways that ended in one group perpetrating genocidal acts upon the other. Read in context, both Geertz's seeming self-contradiction about the impact of culture upon behavior, and the possible implication that he denies the basic character of practical reasoning, melt into air.

\section{Meaning and Power: Hopelessly Entangled and Mutually Implicative}

It is a demonstration of the substance and acuity of their respective assessments that sparks fly when Bush's and Segal's papers are read alongside each other. A pivotal insight that emerges from this encounter is the extent to which Geertz is intentionally eclectic and integrative methodologically, and self-reflectively non-reductive. Grasping what Geertz means when he describes meaning and power as entangled and "mutually implicative" becomes a matter of paying careful attention to the context in which that claim appears. To offer the full quotation: "In what we are pleased to call the real world, "meaning," "identity," "power," and "experience" are hopelessly entangled, mutually implicative, and "religion" can no more be founded upon or reduced to the last, that is, 
"experience," than it can to any of the others" (Geertz 2000, 184). This claim follows several pages of textured description and explication of the revival of the practice of wearing jilbab among younger, urban, mainly college-educated women in Java-women who had grown up in largely "religiously undutiful households," but who, for various reasons, came to embrace the practice.

The jilbab, he explains, is a piece of Islamic dress: "a long, loose-fitting, monochrome gown, reaching to the ankles, designed to conceal the shape of the body, and a long winding scarf, usually white, designed to conceal the hair and neck" (Geertz 2000, p. 180). Geertz begins with reports elicited in direct interviews with the women in question (Brenner 1996). What on the surface are accounts of personal experience and private motivations for changing their dress (i.e. what, in effect, adopting jilbab "means" to each them) are, in fact, implicated in a broad array of interconnected meanings, social relations, and behavioral implications. When thickly described, what appears to the naked eye as merely a "change of dress" for intensely personal religious reasons (the addition of "a few meters of chiffon" in the words of France's Stasi Commission report), is redescribed by Geertz as effecting "a change of the way of being in the world" (Geertz 2000, 184).

What does Geertz mean by that? His description illuminates a complex of contextual forces that impact the women in ways that actually transforms their experiences of the world around them, and in ways that over-run the conceptions of "personal religious experience" they invoke. This complex of forces alters what the women do with their bodies, how they are treated, and what is done to them. Some of these forces are reported directly by the women in interviews and conversations-usually reflecting the dictates of religious commitment and the impact of personal religious experience. Other of these forces are illuminated thematically through third-person analysis of the personal narratives. The latter betray motives and behavioral implications that are not simply "religious," nor fully recognized by the interviewees.

Geertz aims to illustrate how William James' account of "religious experience," in effect, provides an "experience-distant" concept that helps make sense of and analyze what the women describe in terms of "experience near" concepts (namely, intensely personal, deeply private, experience). The bodily practice of wearing jilbab shapes the women's social roles, as well as the ways they are perceived and treated. It shapes and forms the ways they experience the world around them, the ways they experience themselves - what they feel and perceive.

Geertz concludes that James's conception of religious experience remains an illuminating analytical lens for explicating the significance of these cases. And yet, he cautions that the description of this simply in terms of personal religious experience (experience simpliciter) would be intrinsically incomplete if it reduced to the women's reports of their experiences. In short, he thinks that James really must be supplemented by Weber-and in particular, "the Weberian interworking of religious convictions and practical actions," or as Geertz restates it, "the impartibility of belief and behavior" (Geertz 2000, p. 179). Likewise, the analysis would be intrinsically incomplete it were reduced to some other category-whether identity, or power, or meaning. These categories are, rather, "hopelessly entangled, mutually implicative" (184).

Now, is this "power analysis" per se? Clearly, too much would be lost in calling it simply that. That is Geertz's point. Equally clearly, however, attending to and illuminating the formation and habituation of selves, the inter-woven-ness of bodily practices with the constitution and transformation of experience, and all of this through the sociality and coerciveness of acculturation into religious symbol systems-these are things that thick description is capable of attending to, and ostensibly, attending to critically and reflectively. 
To apply any one of the analytical concepts that he identifies as indispensable (identity, experience, power, meaning) in abstraction from the others, or reductionistically, would result in a truncated analysis.

Construed narrowly and in abstraction, Geertz castigated "power analysis"-power conceived as "some sort of featureless, universal force producing an abstract, invariant relationship called 'domination'...." (Geertz 1995, p. 40). Such analytical framing "blocks perception" and leaves the analyst with "the dim banalities of theory." "Of course, the definition of power analysis that Geertz rejects is one that Michel Foucault himself came to reject. ${ }^{7}$ It is instructive that Foucault came to reject the definition of "power" that his work had been saddled with in a way quite similar to Geertz's disavowel of a "theory of meaning" that had come to be identified with his work. ${ }^{8}$ Further realizing their analytical and critical potential for the study of religion requires overcoming precisely such conveniently compartmentalized understandings of them. What Geertz models is an approach that is intentionally non-reductive, eclectic in theoretical appropriations, and improvisational in employing those appropriations. The challenge is to explore and expand upon the descriptive and critical possibilities contained therein. I am pleased to have the opportunity to respond to papers that aid in bringing this pivotal, indispensable, and unfortunately much neglected, task to the fore.

\section{Short Biography}

Jason A. Springs is Assistant Professor of Religion, Ethics, and Peace Studies at the Kroc Institute for International Peace Studies, University of Notre Dame, and Faculty Fellow at Notre Dame's Center for the Study of Religion and Society. His current book project examines the challenges uniquely posed by deep religious diversity for transforming conflict in "post-secular" contexts, with specific attention to dynamics of structural and cultural violence. His broader research interests include restorative justice, ethical and religious dimensions of American Pragmatism and postliberal theology. He is the author of Toward a Generous Orthodoxy: Prospects for Hans Frei's Postliberal Theology (Oxford, 2010), and his articles appear in such journals as Journal of Religious Ethics, The Journal of Religion, Soundings: An Interdisciplinary Journal, Contemporary Pragmatism and Modern Theology.

\footnotetext{
Notes

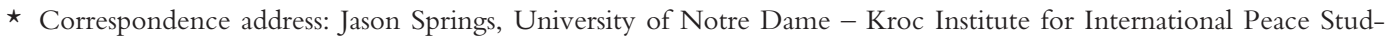
ies, 100 Hesburgh Center, Notre Dame, IN 46556, USA. E-mail: jason.a.springs.2@nd.edu

1 For devastating analysis of Asad's criticisms see Shillbrack (2005). See also Springs (2008).

2 "' 'Love' is an experience-near concept, 'object cathexis' is an experience-distance one. 'Social stratification' and perhaps for most peoples in the world even 'religion' (and certainly 'religious system') are experience distant. 'Caste' and 'nirvana' are experience-near, at least for Hindus and Buddhists. Clearly, this is a matter of degree, not polar opposition'fear' is experience-nearer than 'phobia', and 'phobia' experience nearer than 'ego-dyssyntonic'. ...Confinement to experience-near concepts leaves an ethnographer awash in immediacies, as well as entangled in vernacular. Confinement to experience-distant ones leaves him stranded in abstractions and smothered in jargon" (Geertz 1983, p. 57).

3 The reader with eyes to see will find Geertz, himself, undertaking such a task in, for example, "Person, Time, and Conduct in Bali." "Peoples everywhere have developed symbolic structures in terms of which persons are perceived not baldly as such, as mere unadorned members of the human race, but as representatives of certain distinct categories of persons, specific sorts of individuals." Having glossed how these might create and reinforce social stratification, he continues, "The everyday world in which the members of any community move, their taken-for-granted field of social action, is populated not by anybodies, but by somebodies, concrete classes of determinate persons positively characterized and appropriately labeled. And the symbol systems which define these classes are not given in the nature of things - they are historically constructed, socially maintained, and individually applied" (Geertz 1973, 363).
} 
4 "A motivation is a persisting tendency, a chronic inclination to perform certain sorts of acts and experience certain sorts of feelings in certain sorts of situations, the 'sorts' being commonly very heterogenous and rather illdefined classes in all three cases" (Geertz 1973, p. 96).

5 To be a smoker, to use one of Geertz's examples on this point, is not necessarily to engage in the act of smoking at any determinate moment. It is to have become dispositionally inclined to smoke; to have a proclivity to smoke; to be "in the habit of smoking," and thus, inclined to behave in contextually situated ways that are interwoven with such habits and dispositions (running to the food-mart to pick up a fresh pack, fumbling for matches, keeping up with lighters and breath spray, averting "nicotine fits," sitting in a glass-enclosed cage at the airport, huddling outside non-smoking building entryways during heavy rain or the dead of winter) (Geertz 1973, p. 95).

6 When asked how he would respond to Asad's critique of his work, Geertz said he suspected that Asad was a "power reductionist." When asked if, in opposition to Asad, he viewed meaning as prior to power, Geertz replied, "No. I just do not think that power has any independent existence outside of a cultural or historical context" (Micheelson 2002, p. 9).

7 Alexander Nehamas has demonstrated that, in his later work, Foucault came to view the formation of the self as a way that the relations of power could be reflected upon critically, and even positively utilized (Foucault 1997, pp. 315-6; Nehamas 1998, chap. 6). Hubert Dreyfus claims that Geertz's account of the Balinese cockfight illuminates precisely such background constitutional conditions, and functions to further produce the collective understandings that are lived out in the taken-for-granted daily life of Balinese society (Dreyfus 1993, pp. 353-4). See also the instructive exchange between Joseph Rouse and Hubert Dreyfus (2000), and Springs (2009).

${ }_{8}^{8}$ Foucault states, "[T]he claim that 'you see power everywhere, thus there is no room for freedom' seems to me absolutely inadequate. The idea that power is a system of domination that controls everything and leaves no room for freedom cannot be attributed to me" (Foucault 1997, p. 293). Geertz says, "I do not think meanings are out there to theorize about. One tries to look at behavior, what people say, and make sense of it - that is my theoretical approach to meaning" (Micheelson 2002, 6).

\section{Works Cited}

Asad, T. (1993). The Construction of Religion as an Anthropological Category, In: Genealogies of Religion. Baltimore: Johns Hopkins University Press.

Bowlin, J. \& Stromberg, P. (1997). Representation and Reality in the Study of Culture, American Anthropologist, New Series, 99(1), pp. 123-34.

Brenner, S. (1996). Reconstructing Self and Society: Javanese Muslim Women and 'The Veil', American Ethnologist, 23(4), pp. 673-97.

Davidson, D. (2001). On the Very Idea of a Conceptual Scheme. In: Inquiries into Truth and Interpretation. Oxford: Clarendon Press.

Dreyfus, H. (1993). Nihilism, Art, Technology, and Politics. In: Charles Guignon (ed.), The Cambridge Companion to Heidegger, pp. 289-317. Cambridge: Cambridge University Press.

Foucault, M. (1997). Ethics of the Concern for the Self as a Practice of Freedom. In: Paul Rabinow (ed.), Ethics: Subjectivity and Truth, pp. 281-302. New York: The New Press.

Frankenberry, N. (ed.) (2002). Radical Interpretation in Religion. Cambridge: Cambridge University Press.

Geertz, C. (1968). Islam Observed. New Haven: Yale.

- (1973). The Interpretation of Cultures. New York: Basic Books.

- (1983). Local Knowledge. New York: Basic Books.

. (1995). After the Fact. Cambridge, MA: Harvard University Press.

(2000). Available Light. Princeton: Princeton University Press.

Godlove, T. (1997). Religion, Interpretation, and Diversity of Belief. Macon, GA: Mercer University Press.

Micheelson, A. (2002). 'I don't do systems': An Interview with Clifford Geertz, Method and Theory in the Study of Religion, 14(1), pp. 2-20.

Nehamas, A. (1998). The Art of Living. Berkeley: University of California Press.

Rouse, J. \& Dreyfus, H. (2000). Coping and Its Contrasts, and Responses. In: Mark Wrathall and Jeff Malpas (eds.), Heidegger, Coping, and Cognitive Science, pp. 7-28, 313-322. Cambridge, MA: MIT Press.

Ryle, G. (1949). The Concept of Mind. Chicago: University of Chicago Press.

- (2009). The Thinking of Thoughts: What is le Penseur doing? In: Collected Papers, vol. 2, pp. 494-510. New York: Routledge.

Shillbrack, K. (2005). Religion, Models of, and Reality: Are we through with Geertz? Journal of the American Academy of Religion, 73(2), pp. 429-52.

Springs, J. (2008). What Cultural Theorists of Religion Have to Learn from Wittgenstein, or, How to read Geertz as a Practice Theorist, Journal of the American Academy of Religion, 76(4), pp. 934-69.

—. (2009). 'Dismantling the Master's House': Freedom as Ethical Practice in Robert Brandom and Michel Foucault, Journal of Religious Ethics, 37(3), pp. 419-48. 